\title{
A CIRCULARIDADE DA ESCRITA DE \\ LYGIA FAGUNDES TELLES
}

THE CIRCULARITY OF THE WRITING OF

LyGia FAGUndes TELLES

Carlos Magno Gomes

Universidade Federal de Sergipe

São Cristóvão - Brasil

\begin{abstract}
This essay presents a philosophical reflection about the circularity of Lygia Fagundes Telles' writing from the impersonality of the literary text postulated by the French post-structuralists Michel Foucault, Roland Barthes and Jacques Derrida. As a model, an analysis is carried out of the metanarrativity in the short-story "Senhor Diretor", from the compilation Seminário dos ratos (1977). This text reveals the dissimulation game in which what is said is erased by the murmur of the unsaid. With this, the ambiguous writ-ing processes are recognized that hide references to the outside world, while talking about itself.
\end{abstract}

Keywords: Writing, dissimulation, post-structuralism.

\section{Resumen}

Este ensayo presenta una reflexión filosófica sobre la circularidad de la escritura de Lygia Fagundes Telles por la impersonalidad del texto literario predicada por los posestructuralistas Michel Foucault, Roland Barthes y Jacques Derrida. Como modelo, se analiza la metanarratividad en el cuento "Senhor diretor", de la colección Seminário dos ratos (1977). Este texto expone el juego de disimulación en el cual lo dicho se borra en el murmurio de lo no dicho. Con esto, se reconocen los procesos ambiguos de la escritura, que disimula referencias al mundo externo mientras habla de sí.

Palabras claves: Escritura, disimulación, posestructuralismo.

\section{Resumo}

Este ensaio apresenta uma reflexáo filosófica sobre a circularidade da escrita de Lygia Fagundes Telles pela impessoalidade do texto literário pregada pelos pós-estruturalistas Michel Foucault, Roland Barthes e Jacques Derrida. Como modelo, faz-se a análise da metanarratividade no conto "Senhor diretor”, da coletânea Seminário dos ratos (1977). Esse texto expóe o jogo de dissimulação no qual o dito é apagado pelo murmúrio do não dito. Com isso, reconhecem-se os processos ambíguos da escrita, que dissimula referências ao mundo externo, enquanto fala de si.

Palavras-chave: escrita, dissimulação, pós-estruturalismo. 
A literatura nos convida a pensar filosoficamente a questão da escrita quando traz o debate dos limites do texto artístico como um de seus temas. Esse debate está presente na narrativa pós-moderna, aquela que se refere ao próprio processo de construção do texto, pois pôe "em discussão seu estatuto" de diferentes formas, ao fazer da experimentação com novas linguagens uma prática constante do próprio fazer artístico. Isso é possível quando identificamos, de forma direta ou indireta, a fragmentação do estatuto artístico por meio da "ironização dos gêneros literários", ou da "reescrita", ou da "poética da citação" (VATTIMO, 2002, p. 42). Partindo dessa premissa, este artigo faz uma leitura da circularidade da escrita na ficção de Lygia Fagundes Telles. Como modelo para aplicar esse conceito filosófico, faz-se uma análise das diferentes formas do jogo da linguagem na ficção dessa escritora com destaque para o conto "Senhor diretor", da coletânea Seminário dos ratos (1977).

De forma explícita ou implícita, o jogo metanarrativo faz parte das opçóes estéticas de Lygia Fagundes Telles. Por exemplo, em Ciranda de Pedra (1954), temos os quadros de Otávia, irmá da protagonista Virgínia, funcionado como referência à desestruturação familiar; em Verão no aquário (1963), há os comentários críticos de Raíza, a protagonista transgressora, acerca dos romances de Patrícia, sua mãe. Tais críticas mostram uma repulsa ao romance tradicional de formação feminina que a mãe escreve; em As meninas (1973), identificamos o mal-estar da literatura em Lia, uma feminista guerrilheira, que abandona a escrita de um romance engajado por se sentir traída pela subjetividade da escrita literária; já em As horas nuas (1989), a metanarração pode ser identificada pela construção paródica da biografia de Rosa, uma atriz decadente que faz uma escrita teatral de suas memórias. Todos esses textos trazem os rastros de que o texto literário, ao tentar dizer o social, deixa pistas que ele também fala de si mesmo.

Portanto, a ficção de Lygia Fagundes Telles apresenta diversos elementos estéticos que denunciam a assunção filosófica da fragmentação da linguagem literária. Isso fica mais visível quando analisamos a circularidade de sua escrita por meio da metanarratividade, quando o texto denuncia seu caráter reflexivo (ECO, 2003, p. 199). Partindo dessa concepçáo, vamos propor uma leitura pós-estruturalista do conto "Senhor diretor". Uma das reflexôes que mais se destaca nessa narrativa é o fato de a circularidade do texto denunciar o silêncio da escrita literária.

A seguir, apresentamos os principais conceitos teóricos que dão sustentação a esta análise. Entre eles, ressaltamos o conceito de "suplemento", de Derrida, que destaca a cadeia de remessas diferenciais que abre os sentidos dos signos (DERRIDA, 1999, p. 195); o de "impessoalidade da escrita", de Barthes, que propóe o murmúrio da linguagem como a quebra do elo entre o texto e o autor (BARTHES, 1984, p. 50); e o descentramento do conceito 
de autoria, de Foucault, que valoriza a ideia de diferentes posiçóes autorais em oposição à ideia de um sujeito único (FOUCAULT, 2002, p. 55).

\section{O jogo da literatura}

O jogo do texto literário remete ao autoquestionamento da própria condição da escrita visto que "não há significado que escape, mais cedo ou mais tarde, ao jogo das remessas significantes, que constitui a linguagem. $\mathrm{O}$ advento da escritura é o advento do jogo" (DERRIDA, 1999, p. 8). Nesse sentido, a linguagem pode ser vista como um incômodo contemporâneo, pois ela traz o "impulso espantoso de uma inquietaçáo". Tal inquietação traduz a náo totalizaçáo e se opóe ao conceito de finitude para concentrarse no jogo (DERRIDA, 1997, p. 244). Assim, a circularidade da escrita faz parte da autorreflexão do texto pós-moderno que se opóe a conceitos fixos e definidos de escrita para se enveredar pelos labirintos da ambiguidade da linguagem literária.

Nesta proposta de texto como jogo de linguagem, é imprescindível trazermos à baila os conceitos de rastro como uma relação do signo com o que está fora dele, isto é, o rastro se opóe à lógica do retorno a uma origem simples e plena (NASCIMENTO, 2001, p. 142). Outro conceito importante nesta leitura da circularidade da escrita é o de traço que é simultaneamente e inseparavelmente inscrição e intervalo, resíduo e diferença (JOHNSON, 2001, p. 39). Tais conceitos são atravessados pelo suplemento da escrita, isto é, uma mancha cega no texto, o náo visto que abre e limita a visibilidade da escrita (DERRIDA, 1999, p. 200).

Com base nesses conceitos, fica mais fácil o reconhecimento da circularidade do texto para tentarmos responder como o autor contemporâneo incorpora o pensamento pós-moderno por meio do mosaico textual. Portanto, ao se estudar a construção textual pelo viés filosófico, torna-se fundamental avaliarmos o sentido social da metanarratividade no texto literário. Os recursos estéticos próprios do texto pós-moderno, como a intromissão autoral, o uso da paródia e a polifonia de vozes podem ser explorados como parte do questionamento do próprio status do texto literário na contemporaneidade (VATTIMO, 2002, p. 43).

Nessa perspectiva, Michel Foucault em $O$ que é um autor? trilha uma linha de raciocínio bem pertinente para se ultrapassar a relação unilateral entre autor e obra, pois no processo de produção do texto acontece "o apagamento dos caracteres individuais do sujeito que escreve; por intermédio de todo o emaranhado que estabelece entre ele próprio e o que escreve, ele retira a todos os signos a sua individualidade particular" (FOUCAULT, 2002, p. 36). A perda da individualidade, por que passam os signos no processo metafórico 
da escrita, não significa o esvaziamento do conteúdo textual, mas sim a ampliação dos sentidos literários, visto que a quebra da unilateralidade amplia a complexidade da tessitura artística.

Roland Barthes também nos alerta para a possibilidade de se questionar a relação entre autor e texto quando afirma que é "a linguagem que fala, não é o autor; escrever é, através de uma impessoalidade prévia - atingir aquele ponto em que só a linguagem atua, 'performa', e não 'eu'” (BARTHES, 1984, p. 50). Portanto, a circularidade da escrita presente na metanarratividade reforça o debate da impessoalidade do texto como uma prática contemporânea da literatura. A fragmentação autoral proposta por Michel Foucault serve de subsídio para se pensar a impessoalidade da escrita, pois o autor não é apenas um "eu", mas vários "eus" simultaneamente: "não se define (um autor) pela produçấo de um discurso ao eu produtor, mas por uma série de operaçôes específicas e complexas; não se reenvia pura e simplesmente a um indivíduo real" (FOUCAULT, 2002, p. 55-56).

Tal perspectiva valoriza os rastros e a ambiguidade da linguagem como própria do jogo literário. De acordo com Derrida: "O rastro é verdadeiramente a origem absoluta do sentido em geral. O que vem a afirmar mais uma vez, que não há origem absoluta do sentido em geral. $\mathrm{O}$ rastro é a différance que abre o aparecer e a significação" (DERRIDA, 1999, p. 79-80). Esse questionamento do rastro é fundamental para entendermos o jogo estético que está por trás da escrita literária. Nesse caso, uma boa saída passa a ser a valorização do avesso da escrita.

No jogo da metanarrativa, o avesso da escrita pode ser lido por meio dos suplementos da escrita. O suplemento acompanha a perspectiva da duplicidade do significante que pode ser tanto excesso quanto adição necessária (LECHTE, 2002, p. 126). Isto é, uma adição de um significante para substituir ou suprir uma falta, oferecendo o excesso do significado (SANTIAGO, 1976, p. 88). Como suplementos filosóficos, a repetição e a circularidade da escrita são identificadas por meio das rasuras textuais, pois não há um traço original para qualquer significante. Os significantes da tessitura literária deixam uma camada filosófica suplementar que merece ser identificada, mesmo sem apontar para o que não está dito. O suplemento pode ser usado tanto para completar os sentidos anteriores quanto para ir além do que foi escrito.

Com esse duplo movimento, valorizamos a cadeia suplementar do texto literário. Os suplementos deixam em aberto as diversas fendas do texto e expóem os rastros que remetem um significante a outro, formando a cadeia de remessas constantes de um signo a outro. Essa operaçáo de leitura reconhece que "nunca houve senão suplementos, significaçôes substitutivas que só puderam surgir numa cadeia de remessas diferenciais, o 'real' só sobrevindo, 
só acrescentando-se ao adquirir sentido a partir de um rastro e de um apelo de suplemento etc" (DERRIDA, 1999, p. 194-5). Assim, vamos privilegiar a cadeia de suplementos que nos remete à circularidade do texto.

Nesse movimento de leitura, a cadeia suplementar dos limites da metanarratividade é fundamental para nosso argumento. Por isso, um dos suplementos que se destaca na circularidade da escrita literária é sua capacidade de traição. Por ser independente, a escrita é traidora. Para Derrida, a traição já se manifesta no ato da escrita, vista como um filho sem a presença do pai, "desviado e revoltado, uma desmedida e uma perversão, tanto compadecida e condescendente, apiedando-se de ser desguarnecido, um filho abandonado por seu pai. De qualquer modo, um filho perdido" (DERRIDA, 1997, p. 97).

De acordo com essa perspectiva filosófica, a escrita é cega, ela não é submissa à sua autoria. Ela também traz rastros de outros textos. Ou seja, no processo de construção literária, outras referências textuais não podem ficar de fora no processo de leitura, pois a complexidade da escrita literária não pode ser negada. O logus literário é plural e carrega a maldição de ser apenas uma reprodução sem voz, um eco. Por ser eco, é traiçoeiro, não é transparente, e é assustador enquanto objeto estético, pelas constantes ambiguidades que carrega, pois o leitor nunca chega a um ponto fixo nas possibilidades de leituras.

Com essa constatação, propóe-se uma leitura da circularidade para além das marcaçóes discursivas do texto. Portanto, a hipótese proposta aqui é de que a circularidade da escrita se torna desesperadora para o escritor consciente desses limites do texto literário. Tal argumentação é possível porque o texto literário carrega uma sina trágica de nunca anunciar tudo aquilo a que ele se propóe, pois entre tentar dizer e dizer realmente torna-se uma constatação impossível e, por isso, mordaz. Ora, essa tragicidade pode ser apontada pela consciência que o texto carrega de ser circular e de ser uma escrita fadada ao ponto final.

Por essa perspectiva, o conceito de autor está sendo visto de um lugar ambíguo, que desloca a relaçáo entre autor e obra para analisar o movimento autoral como próprio de um "eu de papel”, - aquele que náo passa de uma personagem de sua escrita: "O eu que escreve o texto nunca é mais também ele, do que um eu de papel” (BARTHES, 1984, p. 59). Esse lugar ambíguo também nos remete ao sujeito que comanda a linguagem. Tal fragmentação da voz autoral aproxima-se da visão de Foucault: "o autor é aquele que dá à inquietante linguagem da ficção suas unidades, seus nós de coerência, sua inserção no real" (1998, p. 28). Escrever e teorizar faz parte do roteiro do texto literário, pois o "discurso nada mais é do que um jogo, de escritura, no primeiro caso, de leitura, no segundo, de troca, no terceiro, e essa troca, essa leitura e essa escritura jamais póem em jogo senão os signos" (FOUCAULT, 1998, p. 49). 
Esse jogo de signos torna-se mais instigante quando o ato de narrar é também abrir/fechar as portas de um labirinto de caminhos possíveis para as diversas interpretações do texto.

No debate sobre o jogo literário, Lygia Fagundes Telles reconhece o compromisso de sua ficção com o social. Por exemplo, nos anos setenta, suas obras registram a barbárie por meio de textos intimistas que abrem espaço para personagens engajadas com a luta política. Em seus depoimentos, a autora reconhece as fronteiras tênues entre sua literatura e o contexto histórico ao mostrar que o fazer literário é composto por imaginaçáo e por arquivos pessoais: "Mais memória ou mais invenção? É impossível separar as águas de vasos comunicantes correndo pelos subterrâneos do inconsciente. Onde acaba a realidade e onde começa o sonho?” (TELLES, 2002, p. 126).

Por ser carregada de ambiguidades, sua ficção tanto traduz o jogo textual quanto dá testemunho da barbárie, explorando uma certa "anarquia formal" que mescla intimismo com configuraçōes autobiográficas (SANTIAGO, 2002, p. 34). Essa preocupação de fazer uma literatura voltada para as questóes políticas é própria de uma "literatura anfíbia", aquela que incorpora a memória coletiva por meio de formas vanguardistas, tendo de um lado o conhecimento do mundo, do outro o exercício de crítica social e de busca de um governo democrático e justo (SANTIAGO, 2004, p. 72).

Mesmo reconhecendo o jogo da linguagem, Lygia Fagundes Telles não abre mão de sua época. Tais registros são parte da memória vivida pela autora, que tinha a denúncia dos problemas sociais como uma estratégia profissional: "participante deste tempo e desta sociedade, tento mostrar as chagas desta sociedade - é o que posso fazer" (TELLES, 2002, p. 90). Sua postura de militante das causas sociais nos remete ao "mal de arquivo" (DERRIDA, 2001), visto que a autora náo deixa de lado os traços que aproximam literatura e realidade. Com essa postura, sua narrativa abre espaço para o texto histórico como parte do pesadelo coletivo.

Tal postura de ficcionalizar os arquivos políticos pode ser vista como uma sofisticada forma de fazer literatura, pois denuncia o estado fascista por meio de depoimentos de suas personagens que registram torturas físicas e psicológicas. Tais imagens são construídas por meio de narrativas ambíguas e esteticamente bem elaboradas, pois forma e conteúdo se complementam. Ao resgatar o arquivo político como um mal do texto literário, a autora não abre mão de narrar as ruínas que envolvem esse arquivo. Com essa perspectiva, sua ficção retoma o fato político tomando como base o princípio do arquivo que "capitaliza tudo, incluindo aquilo que o arruína ou contesta radicalmente seu poder" (DERRIDA, 2001, p. 24).

Em seus textos memorialistas, encontramos pistas da tênue fronteira entre ficção e história. Essa aproximação entre arquivos pessoais e políticos fica 
mais visível quando a autora comenta seu compromisso coletivo: "considero o meu trabalho de natureza engajada, ou seja, comprometido com a nossa condição nesse escândalo de desigualdades sociais" (TELLES, 2002, p. 90). Com essa posição intelectual assumida, observa-se que sua obra apresenta uma visão engajada com a realidade histórica, pois discute formas de narrar, enquanto ressalta o papel político do escritor em uma sociedade desigual. Tais marcas são próprias de uma literatura anfíbia (SANTIAGO, 2004, p. 66).

$\mathrm{O}$ texto de Lygia Fagundes Telles abre o cerco do controle por meio de uma estética que disfarça suas relaçôes com o real quando insinua o exercício da escrita como busca do sonho: "Por que escrevo? Ah, que difícil responder a essa pergunta. Tentarei dar alguma resposta e sei que estou entrando assim numa zona imprecisa. Vaga. O escritor escreve porque tenta recompor, quem sabe? um mundo perdido. Os amores perdidos" (TELLES, 2002, p. 153). Essa tênue fronteira entre o real e o imaginário nos convida a ficarmos sempre atentos ao texto da escritora, como veremos na análise da sofisticada metáfora do silêncio da literatura presente no conto "Senhor diretor", que reforça a ambiguidade da circularidade da escrita.

\section{O silêncio da escrita}

No jogo da criação textual de Lygia Fagundes Telles, identificamos personagens que tentam recompor o mundo perdido. Suas personagens escritoras são atordoadas pela consciência trágica do silêncio do texto literário. Tal consciência está presente no fracasso da escrita de um romance em $A s$ meninas, e no adiamento da redaçáo das memórias da protagonista em $A s$ horas nuas. Neste artigo, retomamos esse fracasso por meio da interpretação das ambiguidades do processo de escrita de uma carta no conto "Senhor diretor". Esta proposta explora o texto como uma partitura que convida o leitor a identificar os artifícios do jogo narrativo para melhor desfrutar as ambiguidades que a circularidade da escrita literária carrega.

No conto "Senhor diretor", a protagonista, Maria Emília, tenta escrever uma carta de denúncia das imoralidades sexuais e das desigualdades sociais, mas acaba narrando suas frustraçóes e decepçóes. Depois de muitas tentativas de se concentrar na escrita da carta e de repetir o conteúdo social, acaba afirmando que nada escreveu, que fugiu das ideias pensadas. Esse silêncio de Maria Emília deixa trilhas da circularidade da escrita, de uma certa repetição que envolve seu desejo de escrita. O leitor se encontra diante de uma circularidade que náo sai do lugar, pois o conto termina com o ponto que foi iniciado.

Nessa circularidade, a repetiçấo é usada em "Senhor diretor" como um recurso ambíguo, pois o desejo de escrita está condensado em uma carta virtual, que não passa de uma elaboração mental de Maria Emília. Nele, há 
um jogo textual em que o dito é apagado e o apagado é dito. Tal ambivalência da escrita também pode ser traduzida pelo termo grego phármakon, que, entre suas muitas significaçôes quer dizer repetição, sedução, envenenamento, droga, antídoto, etc. (NASCIMENTO, 2001, p. 116).

Maria Emília é uma personagem tradicional e preconceituosa, e a ideia de denúncia da qual ela parte é irônica, pois se trata de uma mulher que vigia e controla a sociedade. Como professora, seu papel é manter a ordem e a disciplina. Então, cabe mergulhar um pouco na sua repetição contínua: "Acabei falando em outras pessoas, em mim, espera, vamos começar de novo, sim, a carta" (TELLES, 1998, p. 29). Como dito, a linguagem dessa protagonista é ambígua, pois fala da desmoralizaçáo do Estado ao mesmo tempo em que se constrói como uma tradicional senhora paulistana: "Senhor diretor: antes e acima de tudo, quero me apresentar, professora aposentada que sou. Paulista. Virgem. Fechou os olhos, virgem, virgem verdadeira, não é para escrever mas não seria um dado importante?” (TELLES, 1998, p. 26).

Quando ela faz referência à hipotética carta, temos a exposição do intervalo da escrita, visto aqui como o movimento do que se escreve à medida que se apaga o que se vai escrevendo. Essa fratura da metanarratividade traz o deslocamento das posições discursivas do conto. O discurso de Maria Emília está marcado por um discurso ambíguo, que opera as rasuras entre a narrativa da carta e a do próprio conto. Essa rasura entre o dentro e o fora do conto é própria do jogo textual que está além dessas polaridades.

Em "Senhor Diretor", o jogo entre a escrita literária e a elaboração de uma carta acontece no paralelo, visto que há um processo de um texto dentro do outro. Aos poucos, esses dois eixos vão se aproximando, e, em um determinado momento encontram-se para mostrar o quanto o fio narrativo é só um. Ao mesmo tempo em que os signos são rasurados uns pelos outros, a ideia de traço original se desfaz, já que nas sombras da carta a ideia de circularidade prevalece.

A referência ao próprio texto narrado é um fato muito comum para a literatura que explora a "metanarratividade", que é a "reflexão que o texto faz sobre si mesmo e sobre a própria natureza, ou intrusão autorial que reflete sobre o que se está contando e talvez convide o leitor a compartilhar de suas reflexóes" (ECO, 2003, p. 199). No caso do texto de Lygia Fagundes Telles, consideramos legítimo afirmar que há um jogo textual entre a representaçáo do escritor e seu silêncio presente no jogo do dito e o do negado por Maria Emília. Com o uso da metanarração, esse conto explora um dos conceitos fundamentais da escrita: sua própria motivação, pois "se tudo começa pelo rastro não há rastro originário” (DERRIDA, 1999, p. 75).

Logo, atingir o âmago da escrita é a marca do exercício do escritor que repudia a inocência e a pressa ao produzir seu texto para destacar o incômodo da arte. Isso porque, diferente do que é pregado pela escrita 
realista, a metanarratividade traz uma consciência de que a representaçáo ata-se ao que representa, como se não fosse mais que a sombra ou o reflexo do representado, pois "nesse jogo da representação, o jogo de origem tornase inalcançável” (DERRIDA, 1999, p. 44). Esse jogo é retomado no conto de Lygia Fagundes Telles pelo desejo de uma escrita da carta de denúncia.

Tal ambiguidade entre o silêncio da escrita engajada e a voz subjetiva da protagonista reforça o quanto esse texto está entrecortado por rastros de uma enunciação politizada. Assim, o social vai sendo dito num jogo de negação, como se o traço original, a carta de denúncia, não houvesse, não passasse de um pretexto para a escrita subjetiva na qual Maria Emília se perde. Tudo acontece quando, no dia de seu aniversário, resolve ir sozinha ao cinema. No meio de suas reflexões, há uma crítica ao excesso de cenas de sexo na mídia: "Televisão é outro foco de imoralidade. Anúncios mais sujos, uma afronta" (TELLES, 1998, p. 16).

Ao mesmo tempo em que busca traçar um roteiro da carta, Maria Emília tenta justificar como ela também está inserida nesse processo de prisão a que os meios de comunicação submetem o homem: "digo que a tevê está exorbitando de um modo geral em nos impor a imagem da boçalidade e digo que resisti em comprar uma, bem que resisti, Senhor Diretor. Mas sou sozinha e, às vezes, a solidão. A perigosa solidão" (TELLES, 1998, p. 16). Entre denúncias e memórias, o conto ressalta a subjetividade como um espaço de autorreflexão.

As imposiçóes da indústria cultural e da publicidade - os corpos nus nas capas de revistas, a imposiçấo do "Beba coca-cola", além da "boçalidade da TV" - agridem Maria Emília, que define sua época como de anúncios: "Agora o tempo ficou só de detergentes para as pias, desodorantes para as partes, a quantidade de anúncios de desodorantes" (TELLES, 1998, p. 17). Essa cultura da economia é reconhecida como própria dos tempos pósmodernos. Para Fredric Jameson, a quebra das fronteiras entre cultura e economia está marcada principalmente por interesses econômicos; por isso, cultura e economia coincidem, uma vez que a produção de mercadorias se torna cultura e "a cultura tornou-se profundamente econômica, igualmente orientada para a produção de mercadorias" (JAMESON, 2001, p. 73).

Como visto até aqui, esse conto não é apenas repetiçấo. Ele problematiza o texto engajado socialmente, uma vez que a representaçáo da protagonista traz muitas ambiguidades para o espaço da escrita. Ela questiona a falta de controle do Estado quando chama a atenção para a prostituição das menores: "Mas e a polícia? Não tem mais polícia nesta terra? ... meus céus, mas onde anda o juizado de menores? Em pleno dia" (TELLES, 1998, p. 23). Nessas falas, a resolução dos problemas dos excluídos passa a ser uma "ficção", portanto algo fora de controle. 
Com a omissão do Estado, o excluído é ironicamente representado como o exótico para os políticos de palanques. Daí o testemunho de Maria Emília, que se reconhece como parte da elite e, como tal, está salva: "o senhor, eu - a elite pode estar a salvo. Mas e os outros?” (TELLES, 1998, p. 18). Nesse intervalo da questão "Mas e os outros?", a representação do povo pode ser interpretada como mais um mal-estar para o escritor. Esse problema é retomado em diversos contos da coletânea Seminário dos ratos, de Lygia Fagundes Telles, que ratifica esse mal-estar como um dos principais elementos de sua literatura (GOMES, 2012, p. 57).

Tal dilaceramento das personagens em crise com sua escrita reforça a óptica utópica da literatura, pois remete o leitor ao universo dos excluídos, num processo de exorcismo do fantasma do povo. Nesse sentido, a posição puritana de Maria Emília, uma professora opressora, destaca o jogo irônico que desloca os sentidos sociais e estéticos desse conto. O hipotético diretor pode ser lido dentro de vários referentes textuais e extratextuais como uma indicação irônica à censura imposta pela Ditadura Militar desde a década de 60 .

No meio de suas subjetividades, Maria Emília retoma sempre o fio perdido da escrita: "Já estava escrevendo outra carta, meus Céus, não misturar os assuntos que velhice era outro tópico, agora tinha que se concentrar nessa sufocante vaga de vulgaridade que contaminava até as pedras" (TELLES, 1998, p. 17). O caos da sociedade pode ser traduzido pela metáfora pessimista da contaminação das pedras. No ir e vir, entre o extratextual e o intratextual, o jogo de tecer aponta o quanto o dentro e o fora da escrita se entrelaçam, no jogo da textualidade. O fora, considerado aqui como o elemento histórico, está implícito como um subtexto politizado do social. Isso porque o rastro é o que está fora do signo e não é somente a desaparição da origem. Ele quer dizer algo sempre; por isso, torna-se "a origem da origem" (DERRIDA, 1999, p. 75).

Maria Emília repete uma representação em que a literatura é circulação de saberes, que não há um traço inicial para a escrita, depois de tudo dito, Maria Emília afirma que não escreveu nada, apesar de todo o conteúdo ser conhecido do leitor. Nesse sentido, não há um traço inicial, mas a ambiguidade textual em que Fagundes Telles joga com o ponto inicial do texto. Por isso, "Senhor diretor" usa esse espaçamento entre a escrita e sua representação, quando articula o jogo estético da escrita da carta. Com esse jogo, o duplo da carta funciona como roteiro metanarrativo para se ler o conto: "Era um bom assunto para a carta, a sujeira dos nossos jardins, o único problema é que podia ficar comprida demais" (TELLES, 1998, p. 19). Entre o pretérito e o presente da escrita está mais um signo que pode ser lido na ambiguidade do texto literário.

A repetição da repetiçấo na escrita opóe-se à ideia de mudanças sociais que a protagonista prega. Com isso, uma das peculiaridades da escrita é 
retomada por cada um dos elementos da metanarratividade, dando destaque para a circularidade do texto literário. De acordo com Derrida, "A escritura seria uma pura repetição e, portanto, uma repetição morta que pode sempre nada repetir ou não se repetir espontaneamente a si mesma: ou seja, do mesmo modo, só repetir a si mesma, a repetição vazia e abandonada" (1997, p. 86).

Na cena em que Maria Emília quer começar outra vez a carta, prevalecem as ambivalências da escrita, a circularidade de um texto não feito, de um traço náo executado. Com a suspensão da escrita, Fagundes Telles explora a metanarração outra vez, quando constrói uma personagem que se perde na elaboraçáo do texto. Portanto, em "Senhor Diretor", os suplementos da escrita deixam vestígios de um texto que aponta para o jogo da arte e para o mal-estar do escritor. Isto é, a literatura é vista como um processo instável de formação de sentidos, e também se distancia de imagens fixas para o produto final.

Tal representação do texto dentro do texto tem outros significados quando se analisa o intervalo entre o traço que mostra o fim e o começo da carta: "Acabei falando em outras pessoas, em mim, espera, vamos começar de novo, sim, a carta. Senhor Diretor: antes e acima de tudo. Antes e acima de tudo, Senhor Diretor. Senhor Diretor: Senhor Diretor" (TELLES, 1998, p. 29).

Além das metáforas da produção da escrita, o rastro de origem da teoria e da ficção só pode ser visto numa dobra, num impasse do texto pensado por Maria Emília e o escrito. Entre os pensamentos e a escrita de Maria Emília, há um jogo de linguagem que se aproxima do conceito de escrita no qual "a repetição é o próprio movimento da não-verdade: a presença do ente perde-se nele, dispersa-se, multiplica-se por monemas, ícones, fantasmas, simulacros etc." (DERRIDA, 1997, p. 122). Além desse movimento de repetição, próprio da circularidade, sua literatura deixa pistas do luto que atravessa a tarefa do escritor, pois deixa seu testemunho do luto herdado pelo escritor engajado (GOMES, 2015, p. 283).

\section{Considerações finais}

Em "Senhor diretor", a negação da escrita chega aos limites da experiência textual, pois é trabalhada em um movimento ambíguo de apagar aquilo que vai dizendo. Com essa representação dupla, de dois universos que vão se aproximando, se fundindo, o texto pensado e o texto escrito, o ato da escrita deixa que a linguagem seja redistribuída para desmascarar a circularidade formal por meio da denúncia da degradação social.

Assim, escrita e sociedade se desdobram por meio dessas pistas deixadas por Lygia Fagundes Telles, que, por sua vez, usa um jogo de linguagem que reforça a ambiguidade da escrita literária. Esse duplo jogo pode ser identificado 
quando entrevemos que o texto literário traduz vozes em visóes, pois "toda descrição literária é uma visão. Dir-se-ia que o enunciador, antes de escrever, póe-se à janela, não tanto para ver bem, mas para construir o que vê através de sua própria moldura: o marco da janela faz o espetáculo" (BARTHES, 1992, p. 85).

Com tal dinâmica, Lygia Fagundes Telles constrói uma visão porosa e rasurada da literatura ao tecer uma narrativa que brinca com referentes textuais ao mesmo tempo em que expóe conflitos sociais. Essa dupla moldura reforça o deslocamento do espaço estético e projeta um texto literário de questionamento da repressão política, vivida pelo Brasil naquela época.

Com o final aberto, a versão do silêncio da carta logo é desfeita; contudo, a ambiguidade da escrita se mantém, pois a fronteira dos planos narrados foi quebrada e a marca da circularidade da escrita foi apontada. Nesse jogo, o adiamento dos sentidos é testado de forma ambígua por meio de um jogo no qual, "a não-verdade é a verdade. A não-presença é a presença. A différance, desaparição da presença originária, é, ao mesmo tempo, a condição de possibilidade e a condiçâoo de impossibilidade da verdade" (DERRIDA, 1997, p. 121). Identificar as fronteiras entre o dentro e o fora do texto nos permite traduzir a ambiguidade da linguagem literária. $\mathrm{Na}$ ficção de Telles, esse processo tradutório é guiado pela metanarratividade que nos remete a conceitos diferenciados do jogo literário, destacando-se o sentido de traição e envenenamento que o ato de escrever reserva para o escritor.

Concluindo, além desse precioso jogo do texto dentro do texto, a leitura pós-estruturalista nos permite identificar a ambiguidade da metanarratividade, que, ao se mostrar voltada apenas para uma reflexão interna, deixa rastros de uma sociedade controlada pelo Estado opressor. Fredric Jameson ressalta a forma de pensar para além dos binarismos como própria de uma época que busca as diferenças: "a suplementariedade derrideana [...] exigia esse terceiro estágio, tanto para completar os antecedentes quanto para superá-los e avançar em direção a algo diverso" (JAMESON, 2001, p. 80). Os impasses vividos pela protagonista de Lygia Fagundes Telles nos remetem a esse "algo diverso" da metanarratividade em que mulher, opressão, sexualidade, mídia e patriarcado sáo questionados de dentro da escrita literária de forma sofisticada e pós-moderna. 
BARTHES, R. A morte do autor. In: BARTHES, Roland. O rumor da língua. Trad. de Antônio Gonçalves. Lisboa: Edições 70, 1984.

BARTHES, R. S/Z. Trad. de Lea Novaes. Rio de Janeiro: Nova Fronteira, 1992.

DERRIDA, J. A farmácia de Platão. 2a. ed. Trad. de Rogério Costa. São Paulo: Iluminuras, 1997.

DERRIDA, J. Gramatologia. 2. ed. Trad. de Miriam Chnaiderman e Renato J. Ribeiro. São Paulo: Perspectiva, 1999.

DERRIDA, J. Mal de arquivo: uma impressão freudiana. Trad. De Claudia de Moraes Rego. Rio de Janeiro: Relume Dumará, 2001.

ECO, U. Ironia intertextual e níveis de leitura. In: ECO, Umberto. Sobre literatura. 2a. ed. Trad. de Eliana Aguiar. Rio de Janeiro: Record, 2003.

FOUCAULT, M. Microfísica do poder. Organização e tradução de Roberto Machado. 13. ed. Rio de Janeiro: Graal, 1998.

FOUCAULT, M. O que um autor? Trad. de Antônio Fernando Cascais e Eduardo Cordeiro. 4a. ed. Lisboa: Passagens, 2002.

GOMES, C. A voz dos excluídos em Lygia Fagundes Telles. Revista Letras, Curitiba, n. 86,2012 , p. $47-58$.

GOMES, C. A gramatologia da crítica cultural. Revista da Anpoll, Florianópolis, n. 38, 2015, p. 278-291.

JAMESON, F. 'Fim da arte' ou 'fim da história'?. In JAMESON, F. A cultura do dinheiro. Trad. de Maria Elisa Cevasco e Marcos César de Paula Soares. Petrópolis: Vozes, 2001.

JOHNSON, C. Derrida. Trad. de Raul Fiker. São Paulo: Unesp, 2001.

LECHTE, J. 50 pensadores contemporâneos essenciais. Trad. de Fábio Fernandes. 2a. ed. Rio de Janeiro: DIFEL. 2002.

NASCIMENTO, E. Derrida e a Literatura "Notas" de literatura e filosofia nos textos da desconstrução. 2a. ed. Niterói: EdUFF, 2001.

SANTIAGO, S. (Sup.). Glossário de Derrida . Rio de Janeiro: Francisco Alves, 1976.

SANTIAGO, S. Prosa literária atual no Brasil. In: SANTIAGO, S. Nas malhas da letra. São Paulo: Companhia das Letras, 2002.

SANTIAGO, S. Uma literatura anfíbia. In: SANTIAGO, S. O cosmopolitismo do pobre: crítica literária e crítica cultural. Belo Horizonte: Ed UFMG, 2004. 
TELLES, L. F. Senhor diretor. In: TELLES, L. F. Seminário dos Ratos. 8a. ed. Rio de Janeiro: Rocco, 1998.

TELLES, L. F. Durante aquele estranho chá. Rio de Janeiro: Rocco, 2002.

VATTIMO, G. O fim da modernidade. Tradução Eduardo Brandão. São Paulo: Martins Fontes, 2002.

Carlos Magno Gomes. Professor Associado de Teoria Literária da UFS. Doutor em Literatura pela UnB (2004), com pós-doutorado em Estudos Literários pela UFMG (2013). Bolsista CNPq com diversos artigos publicados em revistas nacionais com enfoque nos estudos comparados, estudos da recepção e estudos de gênero. Editor do periódico acadêmico Interdisciplinar da UFS. E-mail: calmag@bol.com.br 